POLIIICAL ECONOMY RESEARCH INSIITUTE

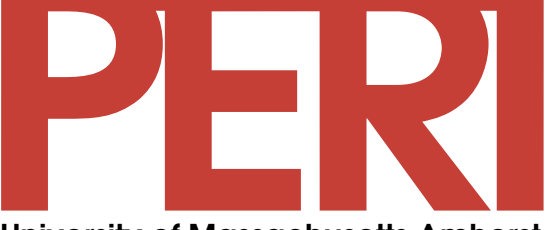

University of Massachusetts Amherst

\title{
STOCK MARKET LIQUIDITY AND ECONOMIC GROWTH: A CRITICAL APPRAISAL OF THE LEVINE/ZERVOS MODEL
}

\author{
Andong Zhu \\ Michael Ash \\ Robert Pollin
}

2002

10th floor Thompson Hall University of Massachusetts Amherst, MA, 01003-7510 Telephone: (413) 545-6355 Facsimile: (413) 545-2921

Email:peri@econs.umass.edu Website:

hHp://www.umass.edu/peri/

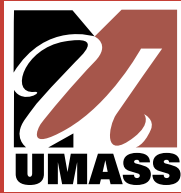




\title{
Preliminary Draft-Comments Welcome
}

\section{STOCK MARKET LIQUIDITY AND ECONOMIC GROWTH: A CRITICAL APPRAISAL OF THE LEVINE/ZERVOS MODEL}

\author{
By Andong Zhu, Michael Ash, and Robert Pollin ${ }^{1}$ \\ Department of Economics and \\ Political Economy Research Institute (PERI) \\ University of Massachusetts-Amherst \\ Amherst, MA 01002
}

September 2002

\begin{abstract}
Levine and Zervos (1998) presented cross-country econometric evidence showing that, in a sample of 47 countries, stock market liquidity contributed a significant positive influence on GDP growth between 1976-93. We show that the Levine-Zervos results are not robust to alternative specifications because of the incomplete manner in which they control for outliers in their data. We show that when one properly controls for outliers, stock market liquidity no longer exerts any statistically observable influence on GDP growth.
\end{abstract}

\section{Introduction}

Should developing countries seek to develop liquid stock markets as a means of advancing economic growth? Economics have long debated this topic, which is understandable, given the considerable policy relevance that flows from how the question is answered. Levine and Zervos (1998) made an influential contribution to this literature through developing an extensive empirical model capable of addressing this question. Their model uses data for 47 countries from 1976 to 1993 . They also incorporate a range of control variables through which they are able to isolate the effects of liquid stock markets on growth from a range of other potential influences. Here they draw constructively from the broader recent literature that uses cross-country multivariate regressions to evaluate the determinants of growth.

Levine and Zervos found that stock market liquidity, measured in various ways, is "a robust predictor of real per capita gross domestic product growth, physical capital growth and productivity growth," after controlling for a range of other potential sources of growth. However, in replicating

\footnotetext{
${ }^{1}$ E-mail contact: Zhu andong@econs.umass.edu, Ash mash@econs.umass.edu, Pollin pollin@econs.umass.edu
} 
the Levine and Zervos model, we conclude that their findings are not robust. Rather their results are driven by outliers in their model, as is strongly suggested by a visual inspection of the residual scatter plot of the stock market liquidity - GDP growth relationship. Levine and Zervos argue that they have adequately handled the issue of outliers in their model, but in fact their treatment is seriously

incomplete, to the point where the statistically significant effects of their stock market liquidity variable disappear after one employs a more careful set of controls for outliers. Our formal replication exercise also shows that the significance of the stock market liquidity variable is completely driven by the contributions of five Asian Tiger economies-Taiwan, South Korea, Hong Kong, Singapore, and Thailand. This finding is also strongly suggested by observing the residual plot. When we control for the effects of these countries with a single dummy variable, the stock market liquidity variable is no longer close to being significant. In short, contrary to Levine and Zervos's conclusions, our replication finds that once one utilizes various appropriate measures to control for outliers, one can no longer conclude that countries will enjoy faster economic growth through operating more liquid stock markets.

Given the fact that the Levine/Zervos results are driven by the experiences of the Asian Tigers, their model actually suggests that it was the unique features of the Asian Tiger financial systems through the early 1990s, and this alone, that made significant contributions to GDP growth for these countries. We comment briefly on this point at the conclusion of the paper, after presenting the results of our replication exercise.

\section{Problems with Controlling for Outliers}

Levine and Zervos present two measures of stock market liquidity. We focus on their preferred measure, which they term "turnover." This is the value of trades of domestic shares on domestic exchanges divided by the value of listed domestic shares. Our overall findings do not change when we use their second measure, "value traded," which equals the value of the trades of domestic shares on domestic exchanges divided by GDP. In Table 1, we present our full set of results, including our exact replication of the Levine/Zervos results in Columns 1-3, and our own 
variations on these models in Columns 4-11 (in the Appendix, we report the outlier control method used in each specification as well as the countries excluded by each method). As we show, we use the same set of control variables as Levine and Zervos in each of these specifications (see Levine and Zervos for the complete definitions of these control variables). In all specifications except the median regression in Column 10, we also follow Levine and Zervos in using heteroskedasticity-consistent standard errors.

The figures in Column 1 exactly reproduce Levine and Zervos's initial results. Thus, they found that a one percentage point higher turnover ratio for a country's stock market in 1976 produces an annual rate of GDP growth that is 0.027 percentage points faster over the period of their data sample, 1976-93. Consider the case of Mexico, for example, whose stock market operated at a turnover ratio of 0.06 in 1976 . According to this initial set of findings, if the 1976 Mexican turnover ratio had instead been at 0.54 , which was the figure for South Korea, Mexico would have raised its average annual growth rate of GDP per capita by a full 1.3 percent through 1993 - from an anemic 0.8 percent rate to the average for the full sample of 2.1 percent. Levine and Zervos state that this central result of their paper is robust to alternative specifications and to the exclusion of outliers, writing "in particular, stock market liquidity remains robustly correlated with growth...after removing potential outliers," (p. 553). They apply two methods for the management of outliers. The first is to use studentized residuals (Belsley, et al., 1980) to test for the influence of leverage points. Columns 2 and 3 report the regression results for a sample excluding observations with high studentized residuals. Column 2 excludes Korea, Jamaica, and the Philippines as outliers. These are the countries that, in an unpublished annex to their paper, Levine and Zervos reported as outliers based on the studentized residual method. However, using the same technique and identical data set as Levine and Zervos, we identified Cote d'Ivoire as the third outlier country while the Phillipines did not warrant exclusion. Thus, in Column 3, we report results with South Korea, Jamaica, and Cote d'Ivoire as outliers. We see that the magnitude and significance of the turnover variable is basically unchanged by this 
difference in specification. In both cases, as in the initial model, stock market turnover remains a significant determinant of GDP growth.

The second method Levine and Zervos use to control for outliers is visual inspection. They examine a scatterplot of residuals from the regression of each of the dependent and key independent variable on all of the other variables and identify outliers on an ad hoc basis following the results of the scaterplot. By this second method, Levine and Zervos identify Taiwan, Korea, Japan, and India as outliers (though they report these as their outliers in the 1996 Working Paper version of their study only). They then report that the regression results are not substantively changed by these exclusions. We reproduce the results of this specification in Column 4. As we see, the coefficient on turnover rises to 0.049 and remains highly significant.

However, we also present in Figure 1 the scatterplot on which Levine and Zervos have based their second outlier control adjustment. An examination of this scatterplot raises two serious questions about the ad hoc choices Levine and Zervos made in excluding countries as outliers. First, it is apparent from the figure that Korea and Taiwan are indeed outliers. However, it is not clear that Japan and India should be treated as outliers, and Levine and Zervos provide no justification for their choice. Second, given that Korea and Taiwan are both obviously outliers, the single-row elimination method of identifying outliers deployed by Levine and Zervos may be inappropriate. The single-row method entails estimating the regression once for each observation, each time omitting exactly one observation. But Belsey, et al. (1980), a standard reference on this issue and the one cited by Levine and Zervos ${ }^{2}$, explains that single-elimination methods may fail to properly identify outliers if more than one are driving the results, even, in some cases, when only one additional data point is exerting leverage.

Because of these problems with Levine and Zervos's methods of controlling for outliers, it therefore becomes necessary to test the robustness of their results through additional outlier control

\footnotetext{
${ }^{2}$ Levine and Zervos cite Belsley et al. directly in their 1996 working paper. In their published 1998 paper, their only reference on the methodology of controlling for outliers is the textbook by Greene (1993). But the discussion by Greene is itself derived from the work presented in Belsley et al, and is clearly referred to as such.
} 
techniques. We pursue seven additional techniques that assess or reduce the leverage of outliers.

These include:

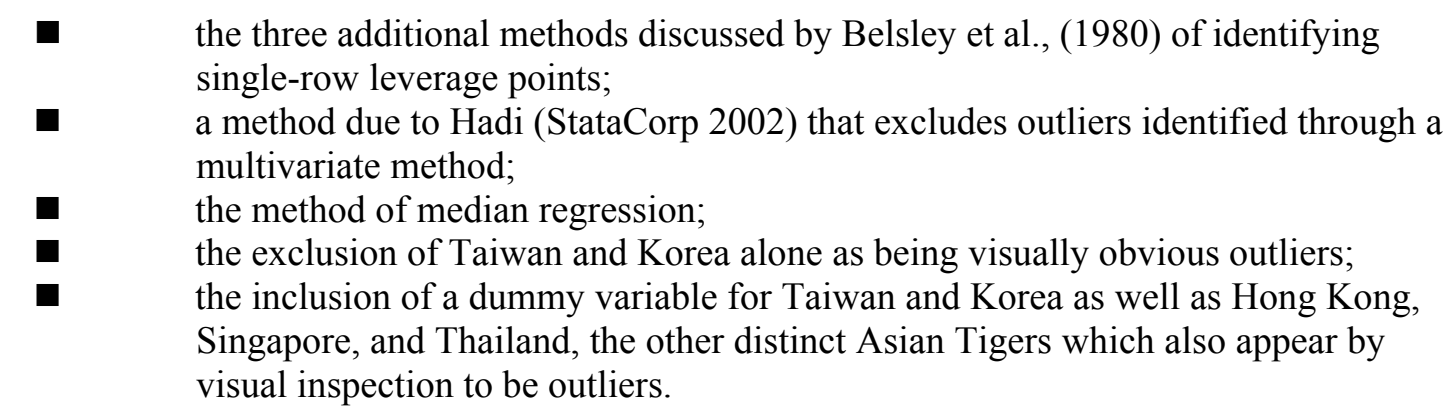

As we will see, Levine and Zervos's basic result of a significant coefficient for the stock turnover variable is not robust to any of these alternative specifications. Indeed, only in two of these alternative specifications does the t-statistic exceed 1.0. Under some of the specifications, the coefficient on the turnover ratio is estimated to be close to zero with substantial precision.

\section{Results with Alternative Outlier Control Methods}

Belsley, et al., (1980) describe three additional techniques in addition to those used by Levine and Zervos for identifying the leverage of single data points: fitted-value analysis; covariance matrix analysis; and hat-matrix diagonal analysis. We estimate the model excluding the outliers identified by each of the Belsley, et al.'s methods and report the results in Columns 5 through 7 of Table 1. As we see, in one case, the coefficient falls as low as 0.013 , and at its highest, the t-statistic reaches 1.30 . But Belsley et al. caution that "residual analysis alone is not a sufficient diagnostic tool" (1980, p. 51) with an illustrative diagram that the single-row elimination can fail to identify any undue leverage if even as few as two outlying data points provide the leverage in the same direction.

Hadi develops an entirely atheoretical method — that is, the dependent and independent variables are not distinguished—for identifying observations that are "far" from the mass of data. Using the Stata Version 7 (2002) implementation of the Hadi method, we identify and exclude from the regression the 14 observations with distance scores that fall in the 5 percent critical range. We report in Column 8 the results from applying this Hadi method. Because the sample size is smaller, 
the substantially higher R-squared value does not necessarily indicate a true improvement in fit. The estimated coefficient on turnover falls to $0.018(0.017)$.

The method of median regression, or least absolute deviations, provides regression estimates that are particularly robust to outliers. Median regression coefficient estimates minimize the sum of absolute residuals (Koenker and Hallock 2001). Outlying points therefore exercise less leverage than they do with the squared residual in OLS regressions. The relative robustness to outliers of these regression techniques is analogous to that of the median and the mean in univariate analysis. We apply median regression and report the estimated parameters and bootstrapped standard errors in Column 9 of Table 1. The pseudo-R-squared value is not directly comparable to the R-squared in the other specifications. The coefficient on turnover falls to $0.023(0.025)$ and is insignificant with a tstatistic of 0.92 .

In terms of visual inspection, as we have discussed, Levine and Zervos exclude Taiwan, Korea, Japan, and India based on the residual scatterplot, though neither Japan or India are obvious choices. Moreover, according Belsey, et al.'s fitted value, covariance ratio and Hat methods respectively, India ranks at $7^{\text {th }}, 33^{\text {rd }}$, and 13 th in its influence as a leverage point, while Japan ranks at $17^{\text {th }}, 19^{\text {th }}$, and $14^{\text {th }}$. The Hadi method ranks India at $10^{\text {th }}$ and Japan at $20^{\text {th. }}$ So the case for excluding Japan and India as outliers appears weak. According to our visual inspection, only Taiwan and Korea appear as obvious outliers. We exclude them from the specification reported in Column 10. Without these two data points, the coefficient on turnover falls to an insignificant $0.018(0.018)$. The adjusted R-squared, no longer buttressed by the excellent performance of the model in explaining Taiwan, falls to 0.41 .

Finally, both the Hadi method for identifying outliers and a visual assessment of a labeled scatterplot suggest that the rapid growing Asian "tiger" economies stand out from the rest of the world. We therefore include a dummy variable for the tigers, which we identify as including Taiwan, Korea, Hong Kong, Singapore, and Thailand. The results of this specification are shown in Column 11. The coefficient on stock turnover decreases to an inconsequential and insignificant $0.002(0.006)$ 
and is more precisely estimated than in the Levine and Zervos specification. We can actually reject the Levine and Zervos result of 0.027 at 95 percent confidence. The addition of this single dummy variable increases the R-squared by more than 50 percent, from 0.50 to 0.77 and the coefficient on the Tiger dummy is a highly significant, $0.045(0.007) .{ }^{3}$ It seems clear then that that the Levine and Zervos results are heavily driven by differences between the high-growth Asian economies and the rest of the world. But it also appears that both within the Asian Tigers and within the rest of the world, stock market turnover has no statistically observable independent effect on GDP growth.

\section{Conclusion}

An ample literature exists on the main sources of the remarkable growth performance of the Asian tigers from the 1970s to the mid-1990s (e.g. The World Bank 1993, Stiglitz 2001, Amsden 2001). This literature explains how the Asian tigers operated with strong government-administered systems of credit allocation and financial regulation, which played a major role in establishing credit flows to productive investments. The Asian financial market model did also operate with heavily traded stock markets, though these markets were less important than the system of administered credit allocation in affecting the flow of funds for investment. This system began to become dismantled in the early 1990s and particularly since the 1997-98 Asian financial crisis. Nevertheless, the results from our replication of the Levine-Zervos model suggest that this unique financial structure was the primary force establishing the positive and significant correlation that we observed between stock market turnover and GDP growth in the overall 47-country sample. Beyond this, our results lead to the conclusion that, at least for the 1976-93 period under consideration, no statistically reliable relationship operated at all between the level of stock market turnover within the countries in the sample and these countries aggregate economic performance as measured by GDP growth.

\footnotetext{
${ }^{3}$ We obtain similar results both through reducing the group of "tigers" to four countries through excluding Thailand, and through increasing the group to six through including Japan.
} 


\section{References}

Amsden, Alice (2001) The Rise of "The Rest": Challenges to the West from Late-Industrializing Economies, New York: Oxford University Press.

Belsley, David A., Kuh, Edwin, and Welsch, Roy E. (1980) Regression diagnostics: identifying influential data and sources of collinearity, New York: Wiley.

Greene, William H. (1993) Econometric Analysis, Englewood Cliffs, NJ: Prentice Hall.

Koenker, Roger and Hallock, Kevin (2001) “Quantile Regression,” Journal of Economic Perspectives, Vol. 15, No. 4, Fall, pp. 143-56.

Levine, Ross and Zervos, Sara (1998) “Stock Markets, Banks, and Growth," American Economic Review, Vol. 88(3), pp. 537-558.

Levine, Ross and Zervos, Sara (1996) "Stock Markets, Banks, and Economic Growth," World Bank Policy Research Working Paper No. 1690, December.

StataCorp (2002) Stata Statistical Software: Release 7, College Station, TX: Stata Corporation.

Stiglitz, Joseph E. (2001) "From Miracle to Crisis to Recovery: Lessons from Four Decades of East Asian Experience," in Stiglitz, Joseph E, and Yusuf, Shahid, ed., Rethinking the East Asian Miracle. Washington, DC: World Bank.

The World Bank (1993) The East Asian Miracle: Economic Growth and Public Policy, Washington, DC: Oxford University Press for The World Bank. 


\section{Appendix: Alternative Regression Specifications and Outliers}

1. The basic Levine/Zervos equation. Full sample.

2. Levine/Zervos application of Belsley, et al. studentized residual method. Excludes Korea, Jamaica, and the Philippines

3. Alternative application of Belsley et al studentized residual method. Excludes Korea and Jamaica as in specfication 2, as well as Cote d'Ivoire substituting for the Phillipines.

4. Levine/Zervos visual inspection method. Excludes Taiwan, Korea, Japan, and India.

5. Belsley et al. Fitted-Value analysis. Excludes Zimbabwe, the Philippines, Cote d'Ivoire, Taiwan, Korea, and Jamaica.

6. Belsley, et al. Covarance ratio method. Excludes Zimbabwe, Argentina, Taiwan, the Philippines, Israel, Luxembourg, Korea, Nigeria, Jordan, Egypt, and Jamaica.

7. Belsley, et al. Hat Matrix method. Excludes Zimbabwe, the Philippines, Argentina, Taiwan, and Israel.

8. Hadi method. Excludes Zimbabwe, Argentina, Jamaica, Nigeria, Israel, Chile, Brazil, the Philippines, Taiwan, India, Egypt, Jordan, Korea, and Cote d'Ivoire.

9. Median regression. Full Sample.

10. Alternative Visual inspection. Excludes Taiwan and Korea.

11. Full sample-With dummy variable for the 5 Tigers: Hong Kong, Korea, Singapore, Taiwan, and Thailand. 
Figure 1. Residual Plot of GDP Growth- Stock Turnover Relationship, 1976 - 93

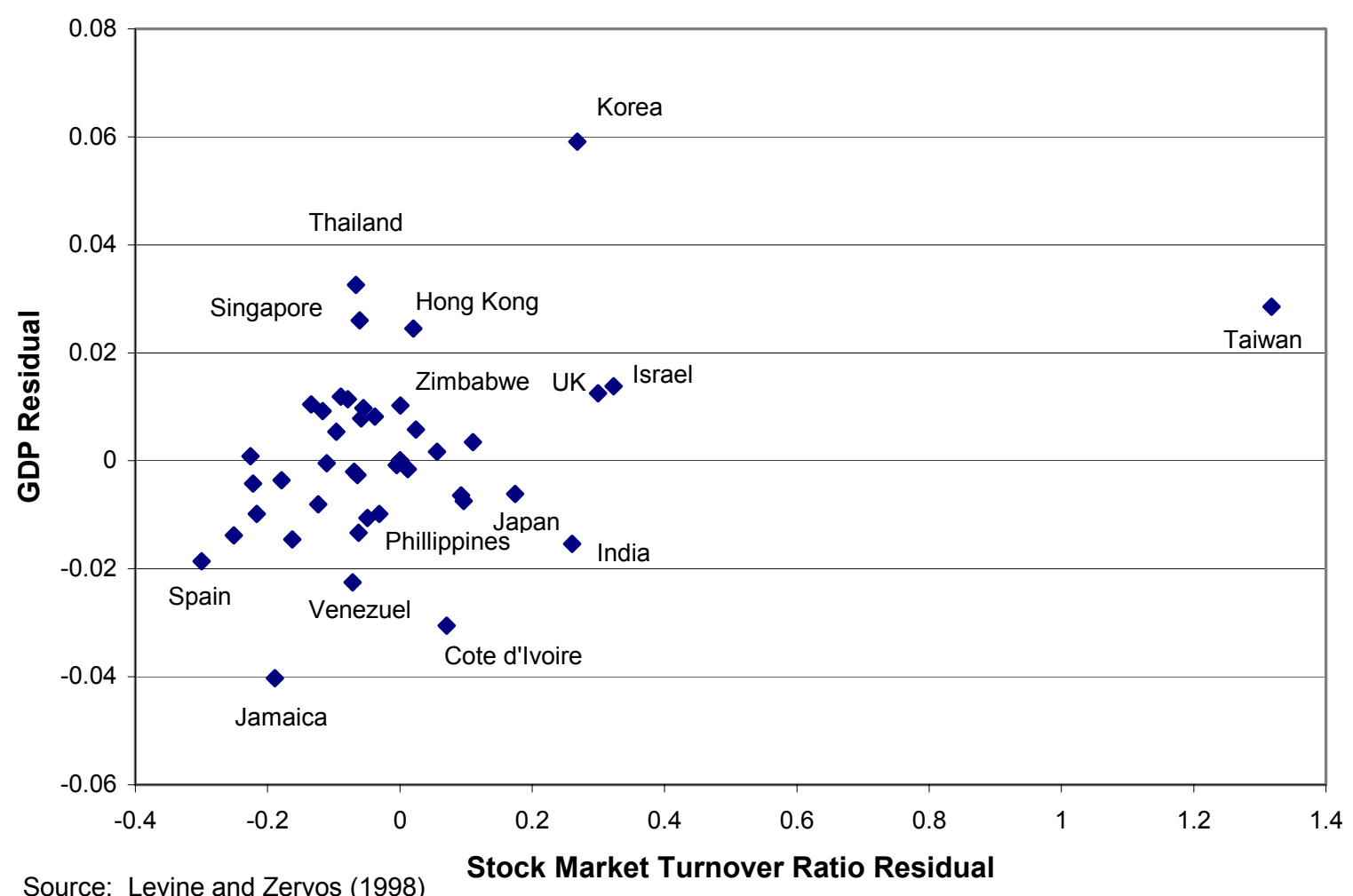

Source: Levine and Zervos (1998) Stock Market Turnover Ratio Residual 
TABLE 1: Stock Market Turnover and GDP Growth Dependent variable is annual growth of GDP per capita, 1976-1993

(Heteroskedasticity-consistent standard errors in parentheses with $\mathrm{p}<0.05=\sim, \mathrm{p}<0.01=*$ )

\begin{tabular}{|c|c|c|c|c|c|c|c|c|c|c|c|}
\hline Model : & 1 & 2 & 3 & 4 & 5 & 6 & 7 & 8 & 9 & 10 & 11 \\
\hline \# obs : & 42 & 39 & 39 & 38 & 36 & 31 & 37 & 28 & 42 & 40 & 42 \\
\hline \multirow[t]{2}{*}{ Constant } & 0.046 & $0.038 \sim$ & $0.065 *$ & $0.062 \sim$ & $0.077 *$ & 0.051 & 0.053 & $0.103 *$ & 0.058 & 0.043 & 0.016 \\
\hline & $(0.025)$ & $(0.022)$ & $(0.019)$ & $(0.029)$ & $(0.025)$ & $(0.030)$ & $(0.029)$ & $(0.023)$ & $(0.041)$ & $(0.027)$ & $(0.020)$ \\
\hline Initial & $-0.014 *$ & $-0.016 *$ & $-0.012 *$ & $-0.015 *$ & $-0.011 *$ & $-0.019 *$ & $-0.016 *$ & -0.019 & $-0.011 \sim$ & $-0.012 *$ & $-0.011 *$ \\
\hline Output & $(0.005)$ & $(0.004)$ & $(0.003)$ & $(0.005)$ & $(0.003)$ & $(0.007)$ & $(0.004)$ & $(0.010)$ & $(0.007)$ & $(0.005)$ & $(0.004)$ \\
\hline \multirow[t]{2}{*}{ Enrollment } & 0.023 & $0.028 *$ & $0.012 \sim$ & $0.020 \sim$ & 0.007 & 0.032 & $0.027 \sim$ & 0.019 & 0.013 & 0.018 & $0.022 \sim$ \\
\hline & $(0.012)$ & $(0.010)$ & $(0.006)$ & $(0.013)$ & $(0.010)$ & $(0.018)$ & $(0.012)$ & $(0.019)$ & $(0.018)$ & $(0.012)$ & $(0.010)$ \\
\hline Revolutions & $-0.035 *$ & $-0.012 *$ & $-0.033 *$ & $-0.043 *$ & -0.021 & -0.018 & 0.003 & -0.019 & -0.035 & $-0.029 *$ & $-0.022 *$ \\
\hline and Coups & $(0.011)$ & $(0.018)$ & $(0.006)$ & $(0.013)$ & $(0.018)$ & $(0.030)$ & $(0.027)$ & $(0.022)$ & $(0.027)$ & $(0.011)$ & $(0.007)$ \\
\hline \multirow[t]{2}{*}{ Government } & -0.062 & -0.046 & -0.021 & -0.064 & 0.000 & -0.053 & -0.095 & -0.022 & -0.013 & -0.042 & -0.002 \\
\hline & $(0.038)$ & $(0.033)$ & $(0.023)$ & $(0.035)$ & $(0.031)$ & $(0.084)$ & $(0.058)$ & $(0.092)$ & $(0.068)$ & $(0.033)$ & $(0.022)$ \\
\hline \multirow[t]{2}{*}{ Inflation } & -0.007 & -0.014 & -0.006 & -0.008 & -0.005 & 0.007 & 0.002 & -0.047 & -0.005 & -0.006 & 0.000 \\
\hline & $(0.006)$ & $(0.010)$ & $(0.006)$ & $(0.007)$ & $(0.009)$ & $(0.020)$ & $(0.016)$ & $(0.073)$ & $(0.033)$ & $(0.007)$ & $(0.006)$ \\
\hline Black Mkt & 0.000 & 0.000 & 0.000 & 0.000 & -0.001 & -0.001 & $-0.001 *$ & $-0.003 \sim$ & 0.000 & 0.000 & 0.000 \\
\hline Premium & $(0.000)$ & $(0.000)$ & $(0.000)$ & $(0.000)$ & $(0.000)$ & $(0.001)$ & $(0.000)$ & $(0.001)$ & $(0.000)$ & $(0.000)$ & $(0.000)$ \\
\hline Banking & $0.013 \sim$ & $0.014 \sim$ & $0.016 *$ & $0.016 *$ & $0.016 *$ & 0.013 & 0.011 & $0.016 \sim$ & 0.01 & $0.014^{*}$ & 0.007 \\
\hline Sector & $(0.005)$ & $(0.006)$ & $(0.005)$ & $(0.006)$ & $(0.005)$ & $(0.008)$ & $(0.006)$ & $(0.007)$ & $(0.009)$ & $(0.005)$ & $(0.004)$ \\
\hline Stock Mkt & $0.027 *$ & $0.018 *$ & $0.02 *$ & $0.049 \sim$ & 0.022 & 0.013 & 0.031 & 0.018 & 0.023 & 0.018 & 0.002 \\
\hline Turnover & (0.009) & $(0.005)$ & $(0.004)$ & $(0.022)$ & $(0.017)$ & $(0.020)$ & $(0.033)$ & $(0.017)$ & $(0.025)$ & (0.018) & $(0.006)$ \\
\hline \multirow[t]{2}{*}{ Asian Tiger } & & & & & & & & & & & $0.045 *$ \\
\hline & & & & & & & & & & & $(0.007)$ \\
\hline R-squared & 0.504 & 0.578 & 0.586 & 0.46 & 0.485 & 0.498 & 0.542 & 0.636 & 0.345 & 0.407 & 0.767 \\
\hline
\end{tabular}

